\begin{tabular}{l} 
SCIENCE \& TECHNOLOGY \\
Journal homepage: http://www.pertanika.upm.edu.my/ \\
\hline PERTANIKA
\end{tabular}

\title{
Characterization of Polyvinylidene Difluoride-based Energy Harvesting with IDE Circuit Flexible Cantilever Beam
}

\section{Khairul Azman Ahmad ${ }^{1 *}$, Noramalina Abdullah², Mohamad Faizal Abd Rahman, Muhammad Khusairi Osman ${ }^{1}$ and Rozan Boudville ${ }^{1}$}

${ }^{1}$ School of Electrical Engineering, College of Engineering, Universiti Teknologi MARA, Cawangan Pulau Pinang, Permatang Pauh, 13500 UiTM, Pulau Pinang, Malaysia

${ }^{2}$ School of Electric and Electronic Engineering, Universiti Sains Malaysia, Engineering Campus, 14300 USM, Penang, Malaysia

\begin{abstract}
Piezoelectric energy harvesting is the process of extracting electrical energy using energy harvester devices. Any stress in the piezoelectric material will generate induced voltage. Previous energy harvester device with stiff cantilever beam was generated low harvested energy. A flexural piezoelectric energy harvester is proposed to improve the generated harvesting energy. Polyvinylidene difluoride is a polymer piezoelectric material attached to a flexible circuit made of polyimide. Four interdigitated electrode circuits were designed and outsourced for fabrication. The polyvinylidene difluoride was then attached to the interdigitated electrode circuit, and a single clear adhesive tape was used to bind them. Four piezoelectric energy harvesters and ultrasonic ceramic generators were experimentally tested using a sieve shaker. The sieve shaker contains a two-speed oscillator, with M1 $=0.025$ $\mathrm{m} / \mathrm{s}$ and M2 $=0.05 \mathrm{~m} / \mathrm{s}$. It was used to oscillate the energy harvester devices. The resulting induced voltages were then measured. Design 4 , with the widest width of electrode fingers and the widest gap between electrode fingers, had the highest power generated

ARTICLE INFO

Article history:

Received: 19 July 2021

Accepted: 13 October 2021

Published: 10 January 2022

DOI: https://doi.org/10.47836/pjst.30.1.32 at an output load of $0.745 \mu \mathrm{W}$ with the M2 oscillation speed. The oscillation speed of the sieve shaker impacted the energy harvester devices as a higher oscillation speed gave higher generated power.
\end{abstract}

E-mail addresses:

khairuluitm75@gmail.com (Khairul Azman Ahmad)

eenora@usm.my (Noramalina Abdullah)

faiza1635@uitm.edu.my (Mohamad Faizal Abd Rahman)

khusairi@uitm.edu.my (Muhammad Khusairi Osman)

rozan259@uitm.edu.my (Rozan Boudville)

*Corresponding author
Keywords: $d 33$ mode polarization, flexible cantilever beam, interdigitated electrode circuit, polyvinylidene difluoride, vibration piezoelectric energy harvesting 


\section{INTRODUCTION}

In recent years, energy harvesting has been an interesting field of study among researchers. Some of the energy harvested were used to keep a large amount of energy for consumption by large-scale electric consumers, and some were used to recycle back the energy capable of supplying energy for sensors or small-scale electric consumers.

Nowadays, many sensors have been installed in various places for measurement. Thus, energy harvesting needs to be done to balance the energy used by these sensors. In the internet of things (IoT) era, sensors were installed on industrial machines, home appliances, and wearable technology for collecting data (Bito et al., 2017; Du et al., 2020; Šolić et al., 2021). In monitoring human health, sensors were installed on the human body (Baloda et al., 2020; Luo et al., 2020). Energy harvester design for human body attachment should be flexible due to the range of human movements. Fakhri et al. (2019) was designed a flexible hybrid structure piezoelectric nanogenerator based on zinc oxide $(\mathrm{ZnO})$ nanorod and polyvinylidene difluoride (PVDF) nanofibers to increase the low generated output. The nanogenerators were tested under load forces of 4, 6.6, 9, and $21 \mathrm{~N}$, and their frequencies were $6 \mathrm{~Hz}$. The generated output was obtained at $356 \mathrm{mV}$ for forces of $4 \mathrm{~N}$, and it was 2.8 times higher than without hybrid piezoelectric.

In this author's work, the energy harvesters were installed on the arm of the human body. They are in amorphous solar cells from Sanyo, which respond to light sources with wavelengths within the $400 \mathrm{~nm}$ to $700 \mathrm{~nm}$ spectrum range. It is for indoor application. A supercapacitor was used to store the harvested energy. The average indoor power harvested was $7.1 \mu \mathrm{W}$, and the average outdoor power was $171.4 \mu \mathrm{W}$ (Fan et al., 2018). Piezoelectric fiber composites (PFC) were installed as a head-mounted chin strap to harvest jaw movements' energy. Each PFC was placed under the chin and attached to a head-mounted device by two elastic rubber straps. Any movement of the mouth or face causes side stress and generates voltage. The maximum power transfer obtained was $7 \mu \mathrm{W}$ (Delnavaz \& Voix, 2014). Another harvester device was composed of multiple piezoelectric stacks with frame and heel-shaped aluminum plates. The energy harvester was designed to be placed underfoot and harvest energy during walking. The piezoelectric stacks contain lead zirconate titanate (PZT) layers with a thickness of $0.1 \mathrm{~mm}$ and silver electrodes with a thickness of $0.1 \mu \mathrm{m}$. The piezoelectric stack has a length of $32.34 \mathrm{~mm}$ with piezoelectric layer sizes of 7.0 $\mathrm{mm} \times 7.0 \mathrm{~mm} \times 0.1 \mathrm{~mm}$ (length $\times$ width $\times$ thickness) as the energy harvesting element of the device. The maximum average power generated with eight piezoelectric stacks were $6 \mathrm{~mW}, 7 \mathrm{~mW}$, and $9 \mathrm{~mW}$ for walking speeds of $4.0 \mathrm{~km} / \mathrm{h}, 4.8 \mathrm{~km} / \mathrm{h}$, and $5.6 \mathrm{~km} / \mathrm{h}$, respectively (Qian et al., 2018). The piezoelectric-based bridge transducers had a length of $32 \mathrm{~mm}$ and a thickness of $2 \mathrm{~mm}$. The maximum power generated by the bridge transducer was $2.1 \mathrm{~mW}$ for a weight of $2267.96 \mathrm{~kg}$ and a frequency of $5 \mathrm{~Hz}$. The piezoelectric material area has affected the harvested energy (Yesner et al., 2019). 
One of the important elements in gaining high generated output is the high conversion performance of mechanical to electrical energy. Azmi et al. (2020) was designed energy harvesting with multi-layered electrospun nanofibers to increase the generated output. The nanofibers have increased the mechanical-to-electrical conversion of sensing elements and improved the generated outputs. The results showed that the piezoelectric materials were based on textile to improve the energy conversion with different piezoelectric coefficients. An electrospun PVDF nanofibers' webs improved 94.49\% electrical output conversion with the force of $2.6 \mathrm{~N}$. The results also showed the PVDF nanofibers improved their generated outputs at different angles of forces hit to nanofibers. A further study on nanofibers was by Bafqi et al. (2021) and showed the improvement of output performance. The improved output voltage when applied pressure with a new energy harvesting design with nanofibers piezo-polymers has shown great sensitivity of generated output in the results. PiezoTester was designed to evaluate the performance of an energy harvesting device based on tapping and bending mode. The sensitivity of the device was calculated based on electrical output for the given load, and the unit was $\mathrm{mV} / \mathrm{N}$. PiezoTester effectively measured the flexibility of PVDF nanofibers polymers.

Piezoelectric energy harvesters were mostly designed in cantilever beams (Fu et al., 2020; Gao et al., 2017; Li et al., 2014). A piezoelectric vibration energy harvester (PVEH) was designed using a bimorph-type cantilever beam. It consists of the electrodes, two piezoelectric layers, and an elastic layer sandwiched between the piezoelectric layers. PVEH with bimorph improved the bending stiffness by incorporating mesh structure to increase the harvested power. The power generated by PVEH was $12.3 \mu \mathrm{W}$ (Tsukamoto et al., 2018). A mechanically plucked piezoelectric energy harvester (Mech-PEH) was designed to improve the energy output. The Mech-PEH used a cantilever beam as the swing of a beam to generate voltage. A cantilever beam consists of rectangular plectra embedded in the outer ring, made from $125 \mu \mathrm{m}$ thick of polyimide film. The flexible plectra led to a high impact on the bimorph cantilever beam and generated output energy of 0.037 $\mathrm{mJ}$ (Kuang \& Zhu, 2017). The PVDF-based thin film was used to harvest more energy due to its capacitance of $570 \mathrm{pF}$. The PVDF cantilever beam has a length of $160 \mathrm{~mm}$, a thickness of $0.9 \mathrm{~mm}$, and a width of $23 \mathrm{~mm}$. The cantilever was attached to a shaker with a frequency of $25 \mathrm{~Hz}$ and a maximum power generation of $1.61 \mu \mathrm{J} / \mathrm{min}$ (Huang \& Chen, 2016). Another design of PVDF cantilever energy harvesting was applied to raindrops. Hao et al. (2020) was an energy harvester device based on a PDVF cantilever and applied to a raindrop. A multi-mode electromechanical was modeled to obtain the dynamic response of the PVDF cantilever due to water droplet impact. A wide range of droplet sizes from $2.4 \mathrm{~mm}$ to $4.6 \mathrm{~mm}$ and velocities impact range of $0.9 \mathrm{~m} / \mathrm{s}$ to $3.4 \mathrm{~m} / \mathrm{s}$ were prepared. The results showed that the droplet splash on a super-hydrophobic beam surface positively affects voltage generation. Small-scaled droplets in splash regime allow higher voltage 
from a super-hydrophobic beam surface than from an untreated hydrophilic beam surface. The flexible substrates positively affect droplet splash in generating electric output and are related to Weber number (We).

This paper designed the flexible piezoelectric with flexible polymer cantilever beam with flexible IDE circuit, PVDF, and adhesive tape. The next section describes the methodology of flexible piezoelectric with flexible polymer cantilever beam with a design approach and experimental setup. Then, the results and discussion are demonstrated with figures and tables to analyze the results. Lastly, the conclusion of this study is made based on the objective that has been approached.

\section{METHODOLOGY}

\section{Design of Interdigitated Electrode Circuit with PVDF}

An interdigitated electrode (IDE) circuit was designed to improve energy conversion from stress to electrical energy. The $d_{33}$ mode polarization method, which is a combination of stress inside piezoelectric and IDE circuits, was used, which is shown in Figure 1.

Figure 1 shows the piezoelectric energy harvester $(\mathrm{PEH})$ consisting of an IDE circuit on polyimide thickness of $161 \mu \mathrm{m}$, PVDF with a thickness of $110 \mu \mathrm{m}$, and adhesive tape with a thickness of $90 \mu \mathrm{m}$. The arrow from the negative electrode to the positive electrode shows the direction of polarization inside the PVDF. At both ends of the cantilever, the beam is tightly clamped to the wall, and between the walls, the cantilever beam was in free movement. The movement up and down of the cantilever beam generated stress inside
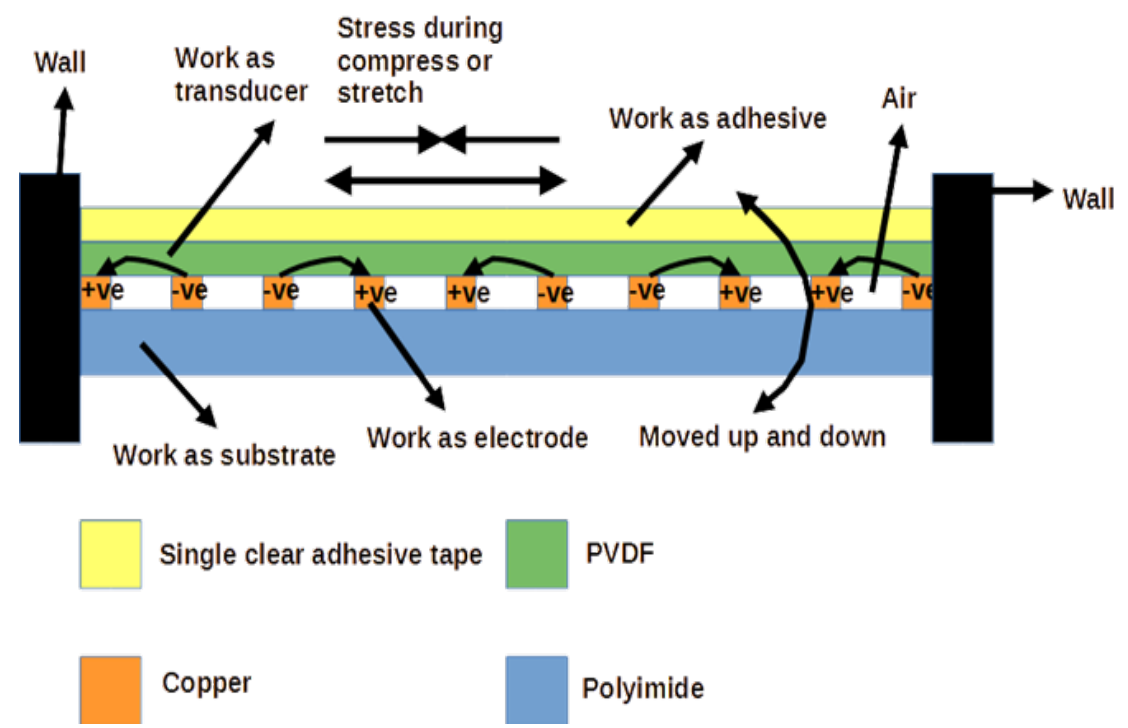

Figure 1. Interdigitated circuit technique with $d_{33}$ mode polarization method 
the PVDF during its compression and stretch. In addition, the process generated induced voltage at the positive terminal electrodes. The substrate used polyimide to reduce stiffness and improve the movement of the cantilever beam. The equation of the induced voltage inside the PVDF is shown in Equation 1 (Shen et al., 2013).

$$
V=E s=-\frac{d}{\varepsilon_{o} \varepsilon} T s
$$

where $V$ is induced voltage, $E$ is the induced electric field, and $s$ is the distance between electrodes. Next, $E$ is equal to $-\left(d / \varepsilon_{o} \varepsilon\right) T$ where $T$ is stress component, $d$ is the piezoelectric coefficient, $\varepsilon_{o}$ is the permittivity of vacuum, and $\varepsilon$ is the relative permittivity of PVDF. The piezoelectric coefficient, $d_{33}$, is higher than $d_{31}$. So, the induced voltage is higher using the $d_{33}$ mode polarization compared to $d_{31}$. The relative permittivity, $\varepsilon$ of PVDF, is lower than other piezoelectric materials. The parameters of the piezoelectric energy harvesters are shown in Table 1.

Table 1

Parameters of piezoelectric energy harvesters

\begin{tabular}{lllllll}
\hline No & Parameter & Design 1 & Design 2 & Design 3 & Design 4 & $\begin{array}{l}\text { Ultrasonic } \\
\text { piezoelectric ceramic } \\
\text { generator }\end{array}$ \\
\hline 1 & $\begin{array}{l}\text { IDE } \\
\text { electrode } \\
\text { width }\end{array}$ & $0.5 \mathrm{~mm}$ & $0.5 \mathrm{~mm}$ & $1 \mathrm{~mm}$ & $1 \mathrm{~mm}$ & - \\
\hline & $\begin{array}{l}\text { IDE gap } \\
\text { between } \\
\text { electrode } \\
\text { fingers }\end{array}$ & $0.5 \mathrm{~mm}$ & $1 \mathrm{~mm}$ & $0.5 \mathrm{~mm}$ & $1 \mathrm{~mm}$ & - \\
\hline $\begin{array}{l}\text { IDE } \\
\text { electrode } \\
\text { length }\end{array}$ & $20.5 \mathrm{~mm}$ & $26 \mathrm{~mm}$ & $25 \mathrm{~mm}$ & $29 \mathrm{~mm}$ & - \\
\hline & & & & & $27 \mathrm{~mm}$ \\
\hline
\end{tabular}

Four different piezoelectric energy harvesting devices, Design 1, Design 2, Design 3, and Design 4, have been devised based on different IDE electrode finger widths, IDE gaps between electrode fingers, and IDE electrode finger lengths. In addition, the ultrasonic generators bought from the market were used as a reference to compare the efficiency of the PEH. The schematic diagram of the IDE fingers and ultrasonic generators is shown in Figure 2. 


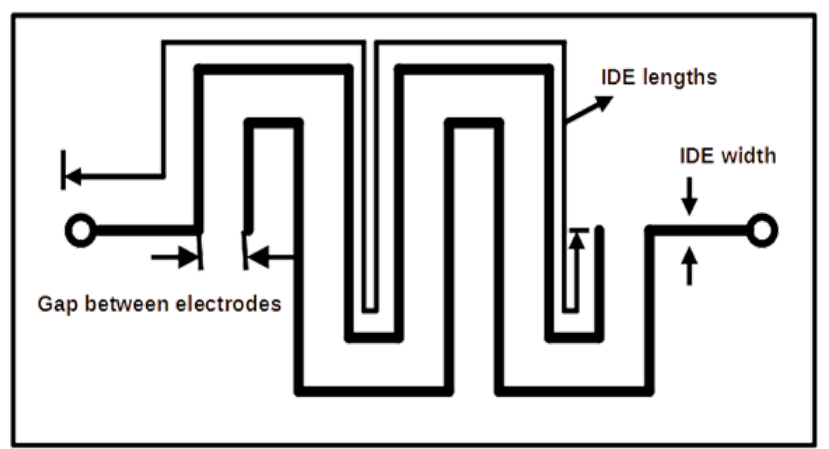

(a)

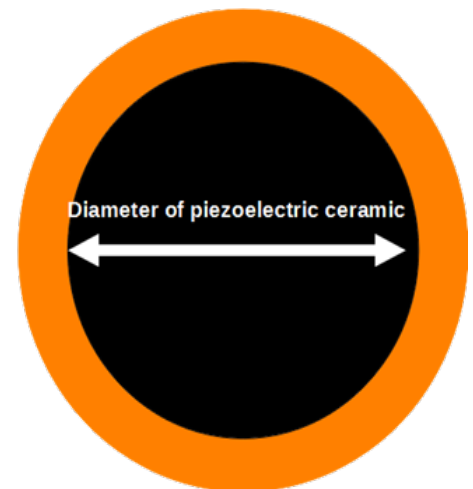

(b)

Figure 2. Schematic diagram of piezoelectric energy harvesters, a) top view of IDE circuits, and b) top view of ultrasonic generators

The harvested energy was on the capacitance of piezoelectric ceramic. The interdigitated electrode can be assumed to behave like a parallel plate capacitor. The electric power between the positive finger and the negative finger is given by Equation 2 (Jasim et al., 2018).

$$
P=\frac{1}{2} C V^{2} \cdot f
$$

where, $P$ is the electric power, $f$ is the frequency of vibration or wave, $C$ is the capacitance of piezoelectric ceramic, and $V$ is the voltage generated during Equation 1 . The capacitance generated on the piezoelectric material can be determined from Equation 3 (Jasim et al., 2018).

$$
C=\frac{\varepsilon_{o} \varepsilon_{r} A}{t}
$$

where, $\varepsilon_{o}$ is the dielectric constant of vacuum $\left(8.885 \times 10^{-12} \mathrm{Farad} / \mathrm{m}\right), \varepsilon_{r}$ is the relative dielectric constant of piezoelectric material in the third axial direction, $t$ is the thickness of the piezoelectric membrane, and $A$ is an area of the piezoelectric membrane. The gap between electrodes fingers can be affected the harvested energy.

Figure 2 shows the schematic diagram of the IDE circuit, specifically, the top view, which shows the gap between electrode fingers, the width of electrode fingers, and the length of electrode fingers. Next, Figure 2 also shows the top view of the ultrasonic generators, including the diameter of piezoelectric ceramic of ultrasonic generators.

The complete fabricated IDE circuit and piezoelectric energy harvesters are shown in Figure 3. The IDE circuit was designed in Proteus and saved in the Gerber file format. The 
file was then sent to a flexible company for outsourcing fabrication. The schematic and fabrication of IDE circuits are shown in Figure $3 a$ and Figure 3b, respectively. Then, PVDF was placed on top of the IDE circuit, and adhesive tape was used to bond the PVDF to the electrode fingers. The completed piezoelectric energy harvesters are shown in Figure $3 \mathrm{c}$.

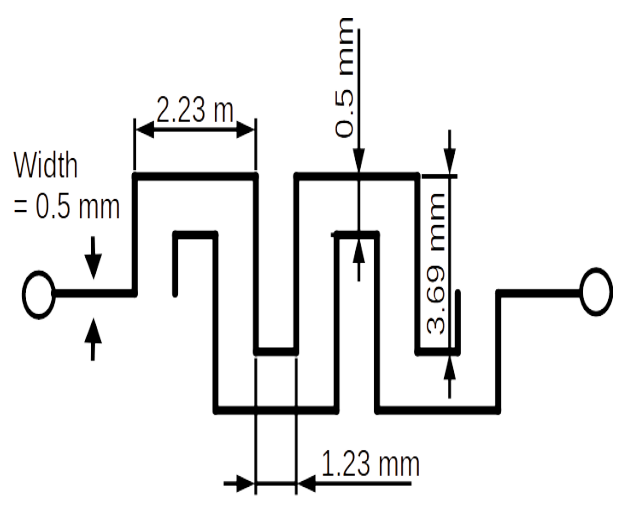

(a)

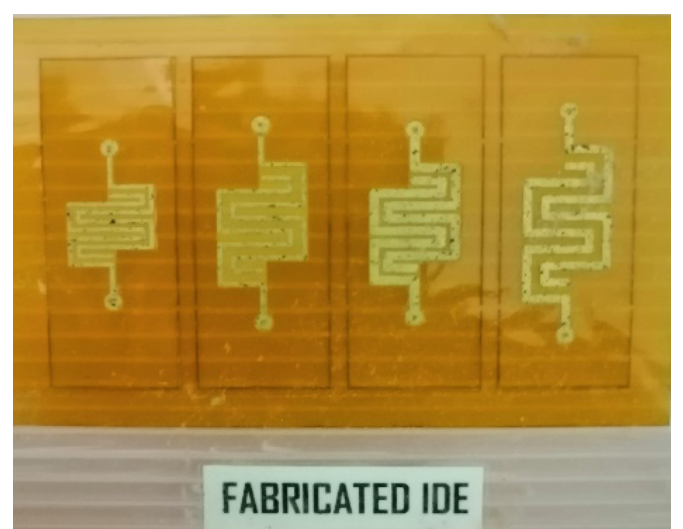

(b)

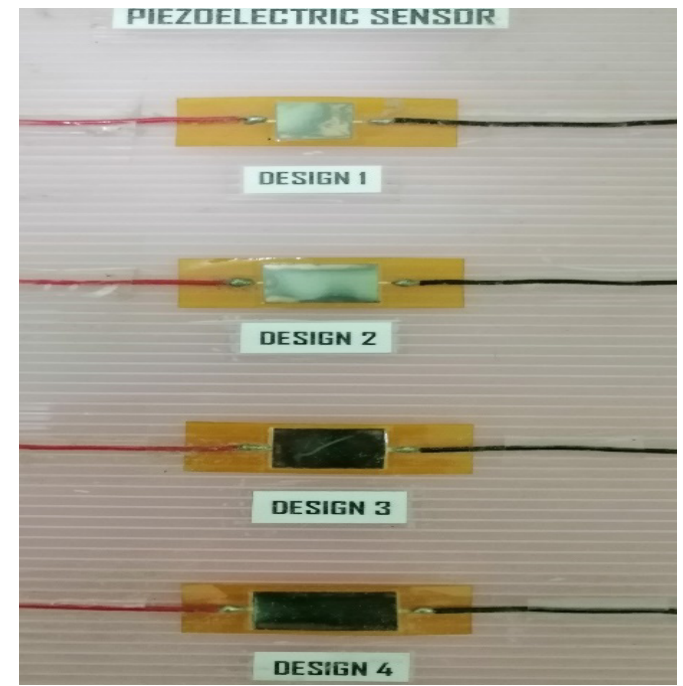

(c)

Figure 3. Piezoelectric energy harvesting devices, a) schematic diagram of IDE circuit design 1, b) top view of fabrication IDE circuits, and c) photo image of piezoelectric energy harvesting devices
The output of PEH was in alternating current (AC) voltage. Therefore, it needs to be converted to direct current (DC) voltage. The readout circuitry, consisting of a rectifier circuit and an energy storage circuit, was developed and is shown in Figure 4.

The readout circuitry has two parts: the rectifier circuit and the energy storage circuit. The rectifier circuit consists of four diode bridges (1N5817). The storage energy circuit consists of a load capacitor (C) with a value of $1 \mu \mathrm{F}$ and a load resistor $(\mathrm{R})$ with a value of $10 \mathrm{k} \Omega$. The induced DC voltage was measured across the load resistor (R). The circuit was designed by Motter et al. (2012). The rectifier circuit was tested and suitable for low-frequency energy harvester. 


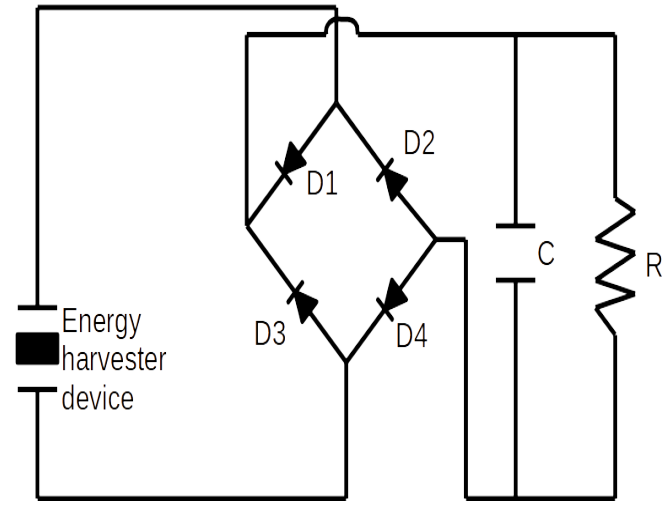

(a)

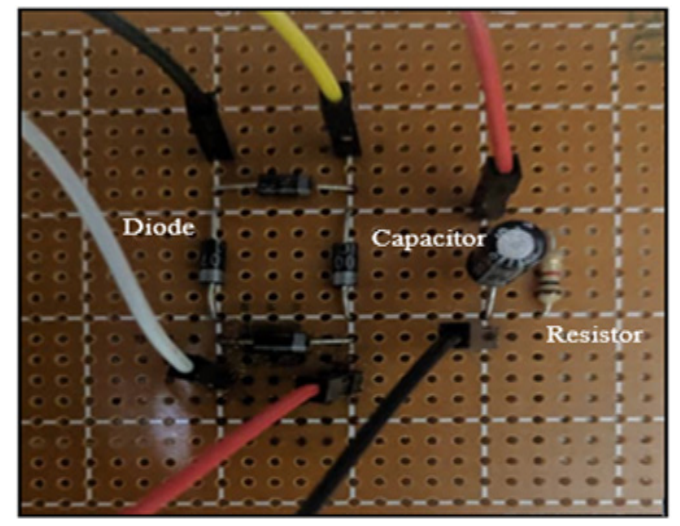

(b)

Figure 4. Readout circuitry, a) schematic diagram of bridge rectifier circuit, and b) photo image of bridge rectifier circuit.

\section{Experimental Setup}

The experiment was carried out to investigate and characterize the effect of vibration on piezoelectric energy harvesters. PEH was placed on top of the sieve shaker at the end of both sides. A metal plate is attached under PEH, and PEH is hung in between the metal plate. Figure 5 shows the setup of the vibration experiment on $\mathrm{PEH}$.

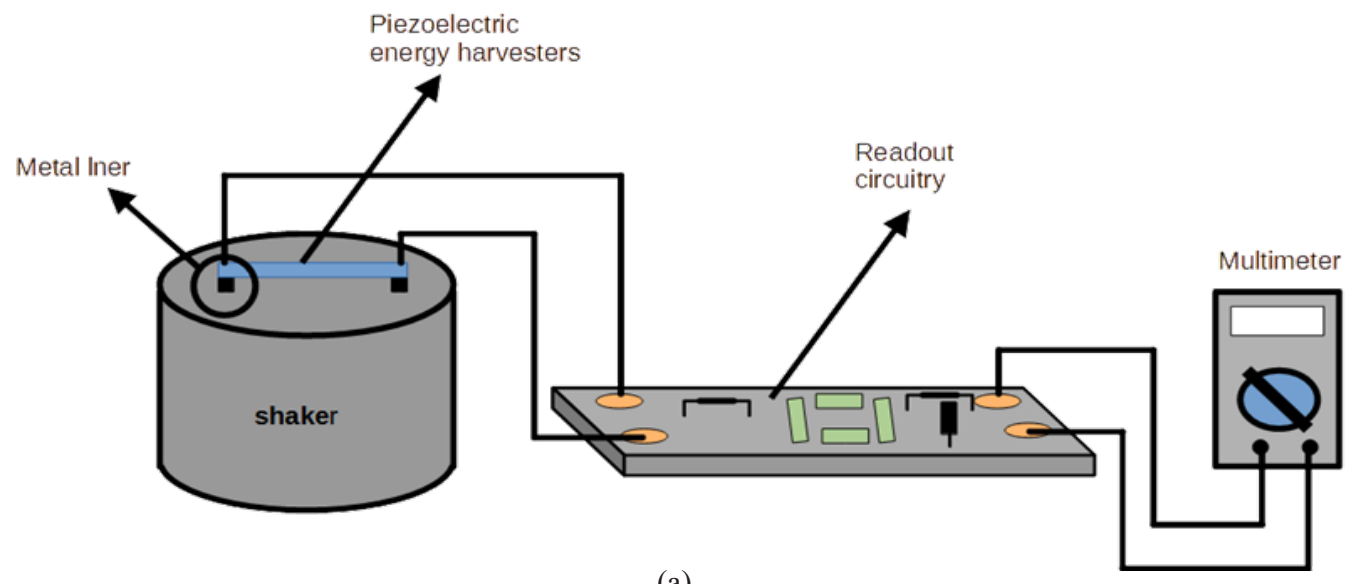

(a) 


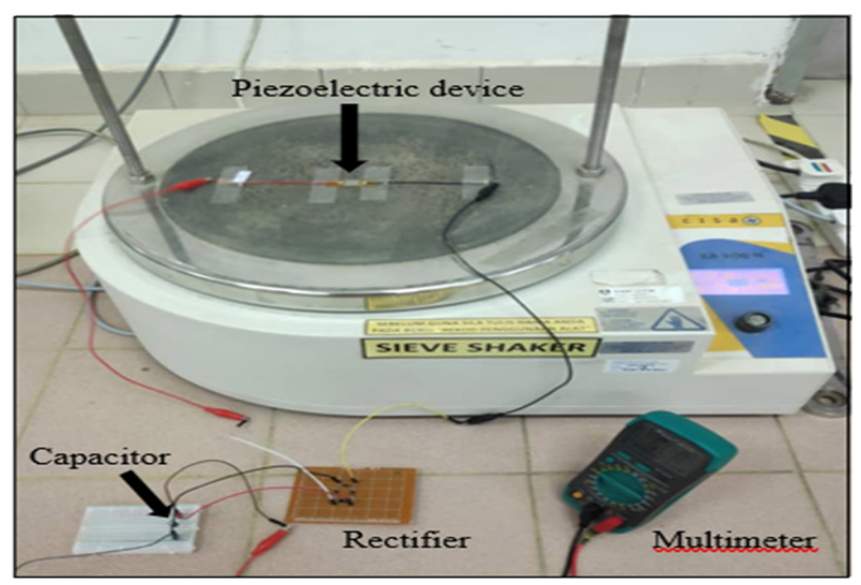

(b)

Figure 5. Vibration experimental setup, a) schematic diagram, and b) photo of experimental setup

The experimental vibration setup consists of a sieve shaker, piezoelectric energy harvesters, readout circuitry, and multimeter. The readout circuitry consists of rectifier circuits and storage circuits. The sieve shaker shakes the piezoelectric energy harvesters at a fixed frequency of $50 \mathrm{~Hz}$. The piezoelectric energy harvesters generated voltage from the stress due to shaker vibration. The alternating current (AC) voltage induced at the piezoelectric energy harvester terminals was converted to direct current (DC) voltage by the rectifier circuit, and the energy was stored in the capacitor. A multimeter was used to read the DC voltage at the output terminal of the readout circuitry. Two amplitudes were used for the shaker, namely $1.0 \mathrm{~mm}$ and $0.5 \mathrm{~mm}$. These two amplitudes represent the speed of up and down oscillation with distances of $1.0 \mathrm{~mm}$ and $0.5 \mathrm{~mm}$. The detailed specification of the vibration setup is shown in Table 2 .

Table 2

Specification of sieve setup for vibration experiment

\begin{tabular}{cc}
\hline Input frequency & $50 \mathrm{~Hz}$ \\
\hline Cycle per second & 50 cycle \\
1 cycle & $\mathrm{A} 1-0.0005 \mathrm{~m}, \mathrm{~A} 2-0.001 \mathrm{~m}$ \\
Speed of oscillation: 50 cycle & $\mathrm{M} 1-0.025 \mathrm{~m} / \mathrm{s}, \mathrm{M} 2-0.05 \mathrm{~m} / \mathrm{s}$ \\
\hline
\end{tabular}




\section{RESULTS AND DISCUSSION}

Four designs of PEH, namely Design 1, Design 2, Design 3, and Design 4, and ultrasonic ceramic generators, were devised to characterize the piezoelectric energy harvesters and ultrasonic ceramic generators. The tabulated results for Design 1 until Design 4 of PEHs and ultrasonic ceramic generators are shown in Table 3. The output voltage results shown in Table 3 were the mean value of three measurement values.

Table 3

Tabulated results of induced DC voltage and power generated for all energy harvester devices

\begin{tabular}{llcccc}
\hline & & \multicolumn{2}{c}{$\begin{array}{c}\text { Mean value of voltage stored } \\
(\mathrm{mV})\end{array}$} & \multicolumn{2}{c}{ Power $(\mu \mathrm{W})$} \\
\cline { 3 - 6 }$(\mathrm{mime})$ & $\begin{array}{l}\text { Name of } \\
\text { energy } \\
\text { harvesters }\end{array}$ & $\begin{array}{c}\text { Speed of } \\
\text { oscillation, } \\
\mathrm{M} 1=0.025 \mathrm{~m} / \mathrm{s}\end{array}$ & $\begin{array}{c}\text { Speed of } \\
\text { oscillation, } \\
\mathrm{M} 2=0.05 \mathrm{~m} / \mathrm{s}\end{array}$ & $\begin{array}{c}\text { Speed of } \\
\text { oscillation, } \\
\mathrm{M} 1=0.025 \mathrm{~m} / \mathrm{s}\end{array}$ & $\begin{array}{c}\text { Speed of } \\
\text { oscillation, } \\
\text { M2=0.05 m/s }\end{array}$ \\
\hline 1 & Design 1 & 10.4 & 12.6 & 0.108 & 0.159 \\
1 & Design 2 & 15.5 & 17.1 & 0.240 & 0.292 \\
1 & Design 3 & 18.9 & 20.1 & 0.357 & 0.404 \\
1 & $\begin{array}{l}\text { Design 4 } \\
1\end{array}$ & 23.0 & 27.3 & 0.529 & 0.745 \\
\hline & $\begin{array}{l}\text { Ultrasonic } \\
\text { ceramic } \\
\text { generators }\end{array}$ & 8.0 & 10.2 & 0.064 & 0.104 \\
\hline
\end{tabular}

Figure 6 illustrates the power generated by all designs of piezoelectric energy harvester and ultrasonic ceramic generator. Two speeds of the oscillator, which are $0.025 \mathrm{~m} / \mathrm{s}$ and $0.05 \mathrm{~m} / \mathrm{s}$, were applied to the sieve shaker. The impact of the vibrator stressed the energy harvesters, which generated power at the output load. The power generated by the oscillation speed of 0.05 was higher than the oscillation speed of 0.025 for every design of piezoelectric energy harvesters and ultrasonic ceramic generators. The speed of oscillation impacted the harvested vibration energy. Design 4 generated the highest power compared to other piezoelectric energy harvester designs and ultrasonic ceramic generators.

Design 4 has wide electrode fingers and a wide gap between the electrode fingers. This work hypothesized the wide gap between the electrode fingers, and the high power generated by the wide gap design in Design 4 proves that hypothesis. Comparing Design 3 and Design 2, Design 3 has wider electrode fingers but a narrower gap between electrode fingers. Design 3 also generated higher power at the output load compared to Design 2. The surface of the electrode area paired to the surface of the PVDF area generated more induced voltage for the narrow gap between the electrode fingers. The highest 
power generated by Design 4 was $0.745 \mu \mathrm{W}$ using an oscillation speed of M2=0.05 m/s. Ultrasonic ceramic generators generated the lowest power at the output load compared to others. Ultrasonic ceramic generators have a wide piezoelectric ceramic area of $27 \mathrm{~mm}$; however, their harvested energy was low due to no cavity or gap between the electrodes. The targeted hypothesis of the proposed design and the result obtained by the proposed design are summarized in Table 4.

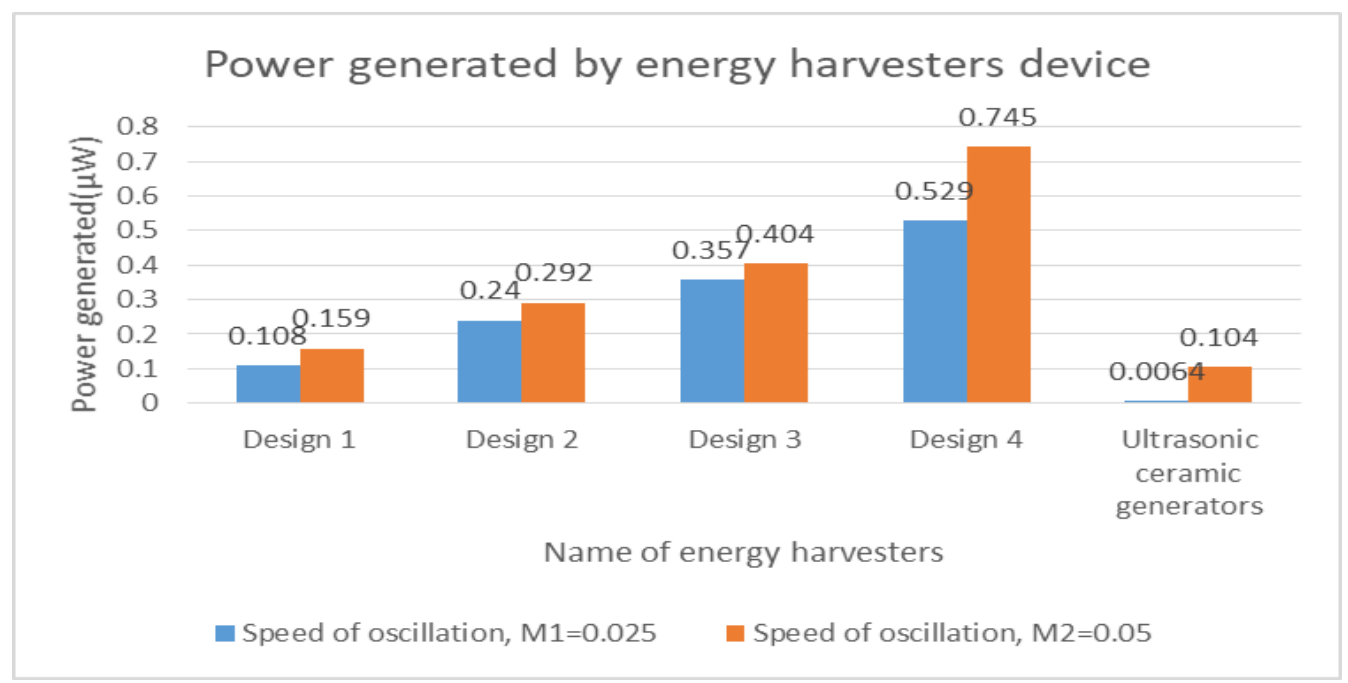

Figure 6. Power generated by energy harvester devices

Table 4

Summary of targeted hypothesis and result obtained by piezoelectric energy harvesters

\begin{tabular}{|c|c|c|c|c|}
\hline Parameter & $\begin{array}{c}\text { Wide gap } \\
\text { between } \\
\text { electrodes fingers }\end{array}$ & $\begin{array}{l}\text { Wide width of } \\
\text { fingers electrode }\end{array}$ & $\begin{array}{l}\text { Output power } \\
\text { generated }\end{array}$ & Hypothesis \\
\hline Design 1 & No & No & Low & As expected \\
\hline Design 2 & Yes & No & $\begin{array}{l}\text { Higher than } \\
\text { design } 1\end{array}$ & As expected \\
\hline Design 3 & No & Yes & $\begin{array}{l}\text { Higher than } \\
\text { design } 2\end{array}$ & Not in hypothesis \\
\hline Design 4 & Yes & Yes & $\begin{array}{l}\text { The highest } \\
\text { compared to } \\
\text { others }\end{array}$ & As expected \\
\hline
\end{tabular}


Table 4 shows that Design 1, with a narrow gap between electrode fingers and narrow width of fingers, generated low output power as expected in the hypothesis. Meanwhile, Design 2, with a wide gap between electrodes but a narrow width of electrode fingers, generated higher output power compared to Design 1, as expected in the hypothesis. The new finding here was Design 3 with a narrow gap between electrode fingers, but a wide width of fingers generated higher output power compared to Design 2. The observation shows that piezoelectric energy harvesters with a wide width of electrode fingers gave more impact for generating output power compared to the wide gap between fingers. Design 4 , with both wide gaps between electrode fingers and width of fingers, generated the highest output power of $0.745 \mu \mathrm{w}$ with an oscillation speed of $0.05 \mathrm{~m} / \mathrm{s}$.

Table 5 shows the performance of previous works using piezoelectric material. Table 5 shows three related works presented; two of them are complicated design and fabrication tools, and one of them is an easy design and fabrication tool similar to this work. Related work no 2 was design pillars fabricated from PDMS and PVDF. Preparation of thin layer of PDMS and PVDF in micro-meter needs a complicated machine and fabrication procedure. A thin layer of PVDF and PDMS gave more flexibility and increased harvested energy. Related work no 3 was designed energy harvester using very thin layer PVDF of $40 \mu \mathrm{m}$ and mesh-core SU-8 of $200 \mu \mathrm{m}$. Fabrication of a thin layer of PVDF needs a complicated machine and process. Furthermore, the fabrication of mesh-core SU- 8 needs a complicated process to prepare the mesh-core. This related work also gave high energy harvesting due to flexible mesh-core and a thin layer of PVDF. The related work no 1 was designed to cantilever beam using bimorph PZT with a thickness of $910 \mu \mathrm{m}$, and the overall thickness of the cantilever beam was $21 \mathrm{~mm}$. This related work was simple fabrication due to their simple fabrication process. Their work has low harvested energy compared to this work. This work used flexible polymer piezoelectric material, PVDF, flexible IDE circuit, adhesive tape as an efficient, flexible cantilever to increase harvested energy. The design using $d_{33}$ mode where the piezoelectric coefficient of $d_{33}$ is higher than the $d_{31}$ piezoelectric coefficient in PVDF material was improved the energy harvested conversion.

\section{Table 5}

Summary table of performance related works

\begin{tabular}{|c|c|c|c|c|c|c|}
\hline No. & Author & Description & $\begin{array}{l}\text { Complexity } \\
\text { of design } \\
\text { and } \\
\text { fabrication } \\
\text { tool }\end{array}$ & $\begin{array}{l}\text { Voltage } \\
\text { (V) }\end{array}$ & $\begin{array}{l}\text { Power } \\
(\mu \mathrm{W})\end{array}$ & $\begin{array}{l}\text { Frequency } \\
(\mathrm{Hz})\end{array}$ \\
\hline 1. & $\begin{array}{l}\text { Motter et } \\
\text { al. }(2012)\end{array}$ & $\begin{array}{l}\text { Cantilever beam consist } \\
\text { of bimorph lead zirconate } \\
\text { titanate (PZT) sandwiched } \\
\text { between copper. }\end{array}$ & Easy & 0.020 & 0.417 & 58 \\
\hline
\end{tabular}


Table 5 (Continue)

\begin{tabular}{|c|c|c|c|c|c|c|}
\hline No. & Author & Description & $\begin{array}{l}\text { Complexity } \\
\text { of design and } \\
\text { fabrication } \\
\text { tool }\end{array}$ & $\begin{array}{l}\text { Voltage } \\
\text { (V) }\end{array}$ & $\begin{array}{l}\text { Power } \\
(\mu \mathrm{W})\end{array}$ & $\begin{array}{l}\text { Frequency } \\
(\mathrm{Hz})\end{array}$ \\
\hline 2. & $\begin{array}{l}\text { Çetin and } \\
\text { Sümer } \\
(2015)\end{array}$ & $\begin{array}{l}\text { Elastomer } \\
\text { pillars consist of } \\
\text { polydimethylsiloxane } \\
\text { (PDMS) and a } \\
\text { piezoelectric polymer } \\
\text { (PVDF). }\end{array}$ & Complicated & N/A & 58.4 & 62 \\
\hline 3. & $\begin{array}{l}\text { Tsukamoto et } \\
\text { al. (2018) }\end{array}$ & $\begin{array}{l}\text { Bimorph piezoelectric } \\
\text { vibration energy } \\
\text { harvester with flexible } \\
\text { mesh-core elastic layer } \\
\text { (PVDF). }\end{array}$ & Complicated & 14.4 & 24.6 & 18.7 \\
\hline 4. & This work & $\begin{array}{l}\text { Polyvinylidene } \\
\text { difluoride-based } \\
\text { Energy Harvesting } \\
\text { with IDE Circuit } \\
\text { Flexible Cantilever } \\
\text { Beam }\end{array}$ & Easy & 0.027 & 0.745 & 50 \\
\hline
\end{tabular}

\section{CONCLUSION}

Piezoelectric energy harvesters were successfully designed and characterized. Four IDE circuits were designed and outsourced for fabrication. The piezoelectric energy harvesters were also successfully fabricated, and the PVDF was attached to the IDE circuit. All piezoelectric energy harvesters and ultrasonic generators were successfully experimentally investigated in a vibration movement. Design 4, with the widest width of electrode fingers and the widest gap between electrodes, generated the highest power at $0.745 \mu \mathrm{W}$. It is concluded that the piezoelectric energy harvesters with wider gaps between electrode fingers and wider widths of fingers can harvest higher energy. The observation also shows that piezoelectric energy harvesters with a wider width of electrode fingers gave more impact to energy harvesters compared to piezoelectric energy harvesters with a wider gap between electrode fingers. The oscillation speed of the sieve shaker also impacted all tested energy harvester devices where higher speed generated high power.

\section{ACKNOWLEDGMENT}

The authors would like to thank the Research Division, Community Industry Network \& Alumni and Training Department, Human Resources Management of Universiti Teknologi MARA, Cawangan Pulau Pinang, for funding the article fee and the lab technicians for their assistance in some parts of the experiments. 


\section{REFERENCES}

Azmi, S., Varkiani, S. M. H., Latifi, M., \& Bagherzadeh, R. (2020). Tuning energy harvesting devices with different layout angles to robust the mechanical-to-electrical energy conversion performance. Journal of Industrial Textiles. https://doi.org/10.1177/1528083720928822

Bafqi, M. S. S., Sadeghi, A. H., Latifi, M., \& Bagherzadeh, R. (2021). Design and fabrication of a piezoelectric out-put evaluation system for sensitivity measurements of fibrous sensors and actuators. Journal of Industrial Textiles, 50(10), 1643-1659. https://doi.org/10.1177/1528083719867443

Baloda, S., Ansari, Z. A., Singh, S., \& Gupta, N. (2020). Development and Analysis of graphene nanoplatelets (GNPs)-based flexible strain sensor for health monitoring applications. IEEE Sensors Journal, 20(22), 13302-13309. https://doi.org/10.1109/JSEN.2020.3004574

Bito, J., Bahr, R., Hester, J. G., Nauroze, S. A., Georgiadis, A., \& Tentzeris, M. M. (2017). A novel solar and electromagnetic energy harvesting system with a 3-D printed package for energy efficient internet-ofthings wireless sensors. IEEE Transactions on Microwave Theory and Techniques, 65(5), 1831-1842. https://doi.org/10.1109/TMTT.2017.2660487

Çetin, H. G., \& Sümer, B. (2015). A flexible piezoelectric energy harvesting system for broadband and lowfrequency vibrations. Procedia Engineering, 120, 345-348. https://doi.org/10.1016/j.proeng.2015.08.631

Delnavaz, A., \& Voix, J. (2014). Flexible piezoelectric energy harvesting from jaw movements. Smart Materials and Structures, 23(10), Article 105020. https://doi.org/10.1088/0964-1726/23/10/105020

Du, S., Jia, Y., Zhao, C., Amaratunga, G. A. J., \& Seshia, A. A. (2020). A nail-size piezoelectric energy harvesting system integrating a MEMS transducer and a CMOS SSHI circuit. IEEE Sensors Journal, 20(1), 277-285. https://doi.org/10.1109/JSEN.2019.2941180

Fakhri, P., Amini, B., Bagherzadeh, R., Kashfi, M., Latifi, M., Yavari, N., Kani, S. A., \& Kong, L. (2019). Flexible hybrid structure piezoelectric nanogenerator based on $\mathrm{ZnO}$ nanorod/PVDF nanofibers with improved output. RSC Advances, 9(18), 10117-10123. https://doi.org/10.1039/C8RA10315A

Fan, D., Ruiz, L. L., Gong, J., \& Lach, J. (2018). EHDC: An energy harvesting modeling and profiling platform for body sensor networks. IEEE Journal of Biomedical and Health Informatics, 22(1), 33-39. https://doi. org/10.1109/JBHI.2017.2733549

Fu, J., Hou, Y., Zheng, M., \& Zhu, M. (2020). Flexible piezoelectric energy harvester with extremely high power generation capability by sandwich structure design strategy. ACS Applied Materials \& Interfaces, 12(8), 9766-9774. https://doi.org/10.1021/acsami.9b21201

Gao, S., Zhang, G., Jin, L., Li, P., \& Liu, H. (2017). Study on characteristics of the piezoelectric energyharvesting from the torsional vibration of thin-walled cantilever beams. Microsystem Technologies, 23(12), 5455-5465. https://doi.org/10.1007/s00542-017-3336-6

Hao, G., Dong, X., Li, Z., \& Liu, X. (2020). Dynamic response of PVDF cantilever due to droplet impact using an electromechanical model. Sensors, 20(20), Article 5764. https://doi.org/10.3390/s20205764

Huang, H. H., \& Chen, K. S. (2016). Design, analysis, and experimental studies of a novel PVDF-based piezoelectric energy harvester with beating mechanisms. Sensors and Actuators A: Physical, 238, 317328. https://doi.org/10.1016/j.sna.2015.11.036 
Jasim, A., Yesner, G., Wang, H., Safari, A., Maher, A., \& Basily, B. (2018). Laboratory testing and numerical simulation of piezoelectric energy harvester for roadway applications. Applied Energy, 224, 438-447. https://doi.org/10.1016/j.apenergy.2018.05.040

Kuang, Y., \& Zhu, M. (2017). Design study of a mechanically plucked piezoelectric energy harvester using validated finite element modelling. Sensors and Actuators A: Physical, 263, 510-520. https://doi. org/10.1016/j.sna.2017.07.009

Li, H., Tian, C., \& Deng, Z. D. (2014). Energy harvesting from low frequency applications using piezoelectric materials. Applied Physics Reviews, 1(4), Article 041301. https://doi.org/10.1063/1.4900845

Luo, W., Sharma, V., \& Young, D. J. (2020). A paper-based flexible tactile sensor array for low-cost wearable human health monitoring. Journal of Microelectromechanical Systems, 29(5), 825-831. https://doi. org/10.1109/JMEMS.2020.3011498

Motter, D., Lavarda, J. V., Dias, F. A., \& da Silva, S. (2012). Vibration energy harvesting using piezoelectric transducer and non-controlled rectifiers circuits. Journal of the Brazilian Society of Mechanical Sciences and Engineering, 34, 378-385. https://doi.org/10.1590/S1678-58782012000500006

Qian, F., Xu, T. B., \& Zuo, L. (2018). Design, optimization, modeling and testing of a piezoelectric footwear energy harvester. Energy Conversion and Management, 171, 1352-1364. https://doi.org/10.1016/j. enconman.2018.06.069

Shen, Z., Lu, J., Tan, C. W., Miao, J., \& Wang, Z. (2013). D33 mode piezoelectric diaphragm based acoustic transducer with high sensitivity. Sensors and Actuators A: Physical, 189, 93-99. https://doi.org/10.1016/j. sna.2012.09.028

Šolić, P., Leoni, A., Colella, R., Perković, T., Catarinucci, L., \& Stornelli, V. (2021). IoT-Ready energyautonomous parking sensor device. IEEE Internet of Things Journal, 8(6), 4830-4840. https://doi. org/10.1109/JIOT.2020.3031088

Tsukamoto, T., Umino, Y., Shiomi, S., Yamada, K., \& Suzuki, T. (2018). Bimorph piezoelectric vibration energy harvester with flexible 3D meshed-core structure for low frequency vibration. Science and Technology of Advanced Materials, 19(1), 660-668. https://doi.org/10.1080/14686996.2018.1508985

Yesner, G., Jasim, A., Wang, H., Basily, B., Maher, A., \& Safari, A. (2019). Energy harvesting and evaluation of a novel piezoelectric bridge transducer. Sensors and Actuators A: Physical, 285, 348-354. https://doi. org/10.1016/j.sna.2018.11.013 
